\title{
Improved near real time surface wind resolution over the Mediterranean Sea
}

\author{
A. Bentamy ${ }^{1}$, H.-L. Ayina ${ }^{1}$, P. Queffeulou ${ }^{1}$, D. Croize-Fillon ${ }^{1}$, and V. Kerbaol ${ }^{2}$ \\ ${ }^{1}$ Institut Français pour la Rechercher et l'exploitation de la MER (IFREMER), DOPS, BP 70, 20280 Plouzané, France \\ ${ }^{2}$ BOOST Technologies, 115 rue Claude Chappe, 29280 Plouzané, France
}

Received: 24 March 2006 - Published in Ocean Sci. Discuss.: 13 June 2006

Revised: 20 September 2006 - Accepted: 8 May 2007 - Published: 24 May 2007

\begin{abstract}
Several scientific programs, including the Mediterranean Forecasting System Toward Environmental Predictions (MFSTEP project), request high space and time resolutions of surface wind speed and direction. The purpose of this paper is to focus on surface wind improvements over the global Mediterranean Sea, based on the blending near real time remotely sensed wind observations and ECMWF wind analysis. Ocean surface wind observations are retrieved from QuikSCAT scatterometer and from SSM/I radiometers available at near real time at Météo-France. Using synchronous satellite data, the number of remotely sensed data available for each analysis epoch $(00: 00 \mathrm{~h} ; 06: 00 \mathrm{~h} ; 12: 00 \mathrm{~h}$; 18:00 h) is not uniformly distributed as a function of space and time. On average two satellite wind observations are available for each analysis time period. The analysis is performed by optimum interpolation (OI) based on the kriging approach. The needed covariance matrixes are estimated from the satellite wind speed, zonal and meridional component observations. The quality of the 6-hourly resulting blended wind fields on $0.25^{\circ}$ grid are investigated trough comparisons with the remotely sensed observations as well as with moored buoy wind averaged wind estimates. The blended wind data and remotely wind observations, occurring within $3 \mathrm{~h}$ and $0.25^{\circ}$ from the analysis estimates, compare well over the global basin as well as over the sub-basins. The correlation coefficients exceed 0.95 while the rms difference values are less than $0.30 \mathrm{~m} / \mathrm{s}$. Using measurements from moored buoys, the high-resolution wind fields are found to have similar accuracy as satellite wind retrievals. Blended wind estimates exhibit better comparisons with buoy moored in open sea than near shore.
\end{abstract}

Correspondence to: A. Bentamy

(abderrahim.bentamy@ifremer.fr)

\section{Introduction}

Several processes related to off-shore activities require the knowledge of accurate surface winds and sea states in fine high space and time resolution. The former are both critical for the determination of the dynamical forcing of the ocean, the estimation of ocean surface currents, waves and related boundary layer processes, and the dispersion and drift of oil and other pollutants. This is particularly true for the Mediterranean Sea, which is one of the largest enclosed sea basin in the world. It spans from $30^{\circ} \mathrm{N}$ to $48^{\circ} \mathrm{N}$ in latitude, and $5^{\circ} \mathrm{W}$ to $37^{\circ} \mathrm{E}$ longitude. Its geometry is quite complicated and characterized by the extended mountains on its border and by the presence of several islands. These slopes are often rapidly diving from mountain tops to sea level. This has two mainly consequences on the wind flows. First, it creates coastal turbulences. The presence of big islands (Corsica, Sardinia, Sicily, Crete...) dramatically disrupts the air flows in their vicinity. The second effect of near coast orography is breezes blowing alternatively from land or from sea. This semi diurnal phenomenon is essentially linked to heat, and has thus a greater effect during the summer. The complicated geometry, orography, and meteorology may have a large impact on the accuracy of the surface parameters (Komen et al., 1994). Among the main surface parameters involved in the atmosphere-ocean exchange are the surface wind and the related momentum flux (wind stress and curl). These are routinely provided in near real time by the European National Meteorological Services (NMSs) as well as by the European Centre for Medium range Weather Forecast (ECMWF). The surface winds are also estimated from radars and radiometers onboard satellites and their assimilation allows significant improvement of forecast and analysis NWP products (see for instance Crapolicchio et al., 1995). The spatial resolution of the operational numerical wind model is smoothed, however, and several fine resolutions of about $25 \mathrm{~km}-100 \mathrm{~km}$, requested by wave and oceanic models or by process studies (Queffeulou, 2005), are missed (Chen, 2003).

Published by Copernicus GmbH on behalf of the European Geosciences Union. 
Over the Mediterranean sea, the surface wind vector is characterized by a large spatial and temporal variability. Even though the seasonal signal is quite common to several sub-basins of the Mediterranean sea, significant regional changes in its amplitude and phase are depicted (Bentamy et al., 2005). Indeed, several local wind conditions exist (Brody et al., 1980) and might have remotely impact on the global space and time wind patterns. For instance, several large scale wind regimes have been identified and documented. These include Mistral wind flowing into the Gulf of Lion from the southern coast of France, the Etesian which flows mostly in the Aegean Sea and into the eastern Mediterranean, the north to northeast Bora flowing in the Adriatic sea, and the southeast to southwest Sirocco blowing from the Libyan and Egyptian coasts toward the north into the south-central Mediterranean sea. There are two major winds flowing in the Alboran Channel and through the Strait of Gibraltar: the Westerly and the Levante winds (east to northeast). Using about ten years of remotely sensed wind speed and direction (Bentamy et al., 2002), it is stated that the highest wind conditions are located in Mistral and Etesian regions. Most of Mistral and Etesian wind conditions (determined according to their climatological patterns) are characterized by wind speed higher than $11 \mathrm{~m} / \mathrm{s}$. Their occurrence rate during the winter season (December, January, February) is about $70 \%$ higher than in summer.

To meet the Mediterranean Forecasting System Towards Environmental Predictions (MFSTEP project) requirements, high space and time resolutions of surface wind speed and direction are estimated from merging ECMWF operational wind analyses and near real time remotely sensed wind observations. The resulting wind fields are indicated as the blended near real time wind products. The improvement of surface wind resolution as well as accuracy is also articulated by several international programs (e.g. WCRP (http://www. wmo.ch/web/wcrp/wcrp-home.html), AMMA (http://amma. mediasfrance.org), MERSEA (http://www.mersea.eu.org/)). Previous studies have been made to enhance the spatial and temporal resolutions of regular global wind fields based on blending atmospheric model and radiometer winds (Atlas et al., 1996), or numerical model and scatterometer winds (e.g. Liu et al., 1996; Chin et al., 1998; Millif et al., 1999). The resulting wind fields were estimated from off line satellite wind products. The present work deals with near real time remotely sensed data to meet the operational surface wind production issue. In this study, the surface wind retrievals are derived from the SeaWinds scatterometer onboard QuikScat, and from the Special Sensor Microwave Imager (SSM/I) onboard the Defense Meteorological Satellite Program (DMSP). Previous studies have been carried out to estimate the accuracy of the off line satellite surface wind through comparisons to in-situ and/or numerical model estimates. (e.g. Boutin et al., 1999; Meissner et al., 2001; Bentamy et al., 2002; Ebuchi et al., 2002; Bourassa et al., 2003). For instance, the comparison of moored buoy wind measure- ments and off-line QuikScat wind observations indicates that the remotely sensed winds compare well with in-situ measurements. The rms differences of wind speed and direction are about $1 \mathrm{~m} / \mathrm{s}$ and $23^{\circ}$, respectively, while the correlations exceed 0.86. Quite similar results are found for SSM/I off line wind estimates. The off-line satellite data are then used to investigate the quality of near real time satellite data over the Mediterranean Sea.

The paper is organized as follows: Sect. 2 describes the data used in this study with general statistics. The objective method allowing the calculation of the blended wind fields is presented in Sect. 3. The validation and the spatial and temporal patterns of the blended wind speed and direction are examined in Sect. 4. Finally, a summary with conclusions is presented in Sect. 5 .

\section{Data}

The near real time remotely sensed data including raw measurements (Level 1) and retrieved surface wind vector (level 2) are available at Météo-France. They are made available with a delay less than $4 \mathrm{~h}$ from satellite acquisition.

\subsection{Scatterometer}

The scatterometer principle is described in wide number of scientific and technical papers (see for instance JPL, 2001). The scatterometer antennas emit toward sea surface microwaves, which are scattered by short sea waves (capillary/gravity waves). The latter are strongly related to changes in surface winds. The fraction of transmitted power that returns to the satellite, the backscatter coefficient $\left(\sigma^{\circ}\right)$, is a function of wind speed and direction.

More specifically, QuikScat/SeaWinds has a rotating antenna with two differently polarized emitters: the $\mathrm{H}$-pol with incidence angle of $46.25^{\circ}$ and the V-pol with incidence angle of $54^{\circ}$. The inner beam has a swath width of about $1400 \mathrm{~km}$, while the outer beam swath is $1800 \mathrm{~km}$. The spatial resolution of SeaWinds $\sigma^{\circ}$ (oval footprint) is of $25 \times 35 \mathrm{~km}$. The latter are binned over the scatterometer swath into cells of $25 \times 25 \mathrm{~km}$, called Wind Vector Cell (WVC). There are 76 WVC across the satellite swath, and each contains the center of 10 to 25 measured $\sigma^{\circ}$. The remotely sensed wind vectors are estimated from the scatterometer $\sigma^{\circ}$ over each WVC using the empirical model QSCAT-1 relating the measured backscatter coefficients to surface winds. Every day, about 1.1 million $25-\mathrm{km}$ ocean surface wind vector observations are retrieved from QuikScat measurements covering about $90 \%$ of the Earth surface.

Even though, this study concerns near real time issues, two QuikScat data sources are used. The first one is generated in near real time by National Oceanic and Atmospheric Administration (NOAA/NESDIS: http://manati.orbit.nesdis. noaa.gov), while the second one is generated and provided 
in off-line time by the Jet Propulsion Laboratory (JPL: http: //podaac.jpl.nasa.gov/). This study includes data from the L2A product, related to backscatter measurements, and from the L2B product related to wind vector retrievals. One main difference between NRT and off-line QuikScat products is the spatial resolution of the backscatter coefficient $\left(\sigma^{\circ}\right)$. In NRT products, $\sigma^{\circ}$ is an average of all backscatter coefficients measured by the same beam (fore-inner, fore-outer, aft-inner, aft-outer) and located within a given WVC. In off-line product, each $\sigma^{\circ}$ is given at its nominal spatial resolution. Both L2B products have been calculated using the standard scatterometer method based on the Maximum Likelihood Estimator (MLE) (JPL, 2001). The scatterometer retrieval algorithm estimates several wind solutions for each wind cell. Generally speaking there are four solutions. The ambiguity removal method is then used to select the most probable wind solution. The latter are used in this study. To improve the wind direction, especially in the middle of swath where the azimuth diversity is quite poor, an algorithm called Direction Interval Retrieval with Threshold Nudging (DIRTH) is used too.

SeaWinds is a Ku band radar. Therefore, rain has a substantial influence on its measurements. Previous studies (Sobieski et al., 1999) have shown that the rain impact may attenuate the scatterometer signal resulting in wind speed underestimation, or change the surface shape due to raindrops, allowing an overestimation of the retrieved winds. The QuikScat wind products involve several rain flags determined from the scatterometer observations and from the collocated rain rate derived from radiometers onboard other satellites.

For each QuikScat orbit, NRT and Off-line L2A and L2B data are collocated in space within the same wind vector cell (WVC). It was found (not shown) that both backscatter coefficients $\sigma^{0}$ compare well. The mean bias is about $0.05 \mathrm{~dB}$ and is not statistically significant. The rms value is about $1.10 \mathrm{~dB}$ and is related to the collocation procedure. Indeed, for each WVC, the number of NRT composite $\sigma^{\circ}$ cannot exceed 4 , while the number of $\mathrm{L} 2 \mathrm{~A}$ (egg) $\sigma^{\circ}$ may reach 32. The main discrepancies are found for low $\sigma^{0}$ values related to low surface winds. Excluding these low values reduces the rms of $\mathrm{H}$-pol and of V-pol $\sigma^{0}$ differences to $0.80 \mathrm{~dB}$ and $0.66 \mathrm{~dB}$, respectively.

NRT and Off-line wind products provide two wind speed and direction types. The first one is the standard wind data which have been processed using the Maximum Likelihood Estimator (MLE) method (Long et al., 1991) and median filter ambiguity removal algorithm with the Numerical Weather Prediction data. The second is enhanced wind data processed using the Direction Interval Retrieval with Thresholeded Nudging (DIRTH) algorithm (JPL, 2001). The comparison between Off-line and NRT wind retrievals does not indicate any systematic bias in wind speed or direction. The bias and rms of wind speed and of wind direction differences are quite small. However, some high discrepancies are de- picted in wind direction comparison. They are mainly related to wind speed less than $5 \mathrm{~m} / \mathrm{s}$. Excluding these surface wind conditions the rms difference of wind direction drops to $6^{\circ}$. Further investigations have been performed to characterize the wind speed and wind direction differences as a function of certain parameters, such azimuth angle, WVC index, longitude, and latitude. No significant dependencies have been found. The impact of rain contamination is more significant. Indeed, more than $17 \%$ of $\mathrm{WVC}$ are indicated rain free for NRT wind data, while for off-line wind data, they are indicated rain contaminated. Using only the rain flag provided with NRT wind data increases the rms wind speed difference by about $30 \%$.

To improve rain detection in QuikScat NRT data, the method developed by Portabella et al. (2002), based on the use of MLE estimation calculated from NRT $\sigma^{0}$, is implemented to determine a new NRT rain flag (called hereafter KNMI rain flag). The former impact is investigated through the comparison between available off-line and NRT data both estimated over the same WVC and orbit. Three cases of rain free NRT wind data are considered. They are associated to the use of NRT rain flag, combination of NRT and off-line rain flags, and combination of NRT and KNMI rain flags, respectively. Table 1 summarizes the main statistical parameters characterizing the comparisons of off-line and NRT wind speeds and directions during January 2004 over the Mediterranean Sea. The difference between off-line and NRT wind estimates is low. However, the use of the combination of NRT and KNMI rain flag provides a slight improvement in terms of wind speed as well as in wind direction comparisons. The main impact of KNMI rain flag is found for the high values of off-line and NRT wind difference. Indeed, the number of differences exceeding two times standard deviation of the overall difference $(0.74 \mathrm{~m} / \mathrm{s})$ is reduced by a factor $49 \%$ in the third case. Furthermore, the $95 \%$ percentile of the differences calculated for the three cases is about $1.19 \mathrm{~m} / \mathrm{s}$, $0.87 \mathrm{~m} / \mathrm{s}$, and $0.97 \mathrm{~m} / \mathrm{s}$, respectively.

\subsection{Radiometers}

The SSM/I radiometers onboard the DMSP F13, F14, and F15 satellites provide measurements of the surface brightness temperatures at frequencies of 19.35, 22.235, 37, and $85 \mathrm{GHz}$ (hereafter referred to as $19,22,37$, and $85 \mathrm{GHz}$ ), respectively. Horizontal and vertical polarization measurements are taken at 19,37 , and $85 \mathrm{GHz}$. Only vertical polarization is available from $22 \mathrm{GHz}$. Due to the choice of the channels operating at frequencies outside strong absorption lines (for water vapor) $(50-70 \mathrm{GHz})$, the radiation measured by the antennae is a mixture of radiation emitted by clouds, water vapor in the air and the sea surface, as well as radiation emitted by the atmosphere and reflected at the sea surface. For the estimation of the 10-m wind speed from SSM/I brightness temperatures, the algorithm published by Bentamy et al. (1999) is used. The latter is a slightly modified 
Table 1. Statistical parameters of Off-line and NRT wind speed and wind direction differences according to the use of three rain flags.

\begin{tabular}{lcccccc}
\hline & \multicolumn{3}{l}{ Wind Speed } & \multicolumn{3}{c}{ Wind Direction } \\
& Bias & Rms & Correlation & Bias & Std & Correlation \\
\hline NRT flag & 0.03 & 0.67 & 0.98 & -2 & 22 & 1.78 \\
NRT and off-line flag & 0.00 & 0.51 & 0.99 & -1 & 19 & 1.85 \\
NRT and KNMI flag & 0.02 & 0.51 & 0.99 & -1 & 22 & 1.84 \\
\hline
\end{tabular}

version of the Goodberlet et al. (1989) algorithm and includes a water vapor content correction. One can notice that wind directions are not retrieved from SSM/I measurements. The SSM/I wind speeds are calculated over swaths of 1394$\mathrm{km}$ width, with a spatial resolution of $25 \mathrm{~km} \times 25 \mathrm{~km}$. The retrieved wind speed was calculated from brightness temperature measurements provided by NASA Marshall Space Flight Center (MSFC). Previous studies investigated the accuracies of the retrieved SSM/I winds through comparisons with moored buoy wind measurements in several oceanic regions (Bentamy et al., 2002). The standard error values of $\mathrm{SSM} / \mathrm{I}$ wind speeds with respect to the buoy winds are less than $2 \mathrm{~m} / \mathrm{s}$. The bias values do not exceed $0.20 \mathrm{~m} / \mathrm{s}$.

The NRT brightness temperatures as well as retrieval winds were compared to MSFC data. No significant differences were found. Furthermore, the NRT winds are compared to Remote Sensing System (http://www.remss.com) data. The latter were used and validated by several authors in various oceanic regions (see for instance Meissner et al., 2001). NRT and RSS swath wind data are collected over the Atlantic Ocean and the Mediterranean sea during January 2004. Only validated wind data (about 3900000 for NRT and 4200000 for RSS) based on quality control related to each wind source, are used. The main result is that RSS and NRT data present an almost identical distribution especially for wind speeds between 3 and $18 \mathrm{~m} / \mathrm{s}$ (more than $90 \%$ of total data); NRT and RSS provide quite similar winds with close mean and standard deviation values. The Student's test, estimating the statistical significance between two mean values, indicates that SSM/I NRT and RSS means are the same with $95 \%$ confidence. The main discrepancy between the two sources is found out for high winds. More than $2.5 \%$ of RSS wind data exceed $18 \mathrm{~m} / \mathrm{s}$ whereas there are only $0.1 \%$ for NRT. Most of the cases of high surface winds and significant difference between RSS and NRT are related to rain detection. In NRT, the rain flag seems to reject several high wind estimates.

\section{Objective method}

The method aims to estimate gridded wind fields from ECMWF operational surface wind analysis and from near real time satellite surface parameter observations, at regular space and time resolutions. The method is based on the kriging approach analyzing the differences between ECMWF data and satellite observations.

\section{$3.1 \quad$ Numerical procedure 3.1}

Let us assume that:

$X_{a}=\tilde{X}+\varepsilon_{a}$ and $X_{b}=\tilde{X}+\varepsilon_{b}$

Where $X_{a}$ is the expected analysis value estimated at a grid point of $\delta h$ degrees in longitude and latitude and over $\delta t \mathrm{~h}$. Three spatial resolutions of $\delta h$ are considered: $0.25^{\circ}, 0.5^{\circ}$, and $1^{\circ}$, while the temporal resolutions $\delta t$ are: $6 \mathrm{~h}, 12 \mathrm{~h}$, and $24 \mathrm{~h}$.

$X_{b}$ represents the background vector (from ECMWF) available every $6 \mathrm{~h}$ and over grid point of $0.5625^{\circ}$ degrees in longitude and latitude of the global ocean. For $\delta h$ of $0.25^{\circ}$, the ECMWF analysis is linearly interpolated. For $\delta h$ of $1^{\circ}$, ECMWF data are averaged over the grid point.

$\tilde{X}$ is the true surface parameter, while $\varepsilon_{a}, \varepsilon_{b}$ are the associated errors of $X a$ and $X_{b}$, respectively.

Therefore $X_{a}=X_{b}+\tilde{\varepsilon}$, where $\tilde{\varepsilon}$ is a combination of $\varepsilon_{a}$ and $\varepsilon_{b}$. Its values are estimated from remotely sensed observations as follows:

$\hat{\varepsilon}_{i}=\frac{1}{\left(t_{b}-t_{a}\right)} \int_{t a}^{t b}\left(\sum_{j=1}^{N} \lambda_{j}\left(X_{o}^{j}\left(x_{j}, y_{j}, t\right)-X_{b o}^{j}\left(x_{j}, y_{j}, t\right)\right)\right) d t$

$\hat{\varepsilon}_{i}$ stands for $\tilde{\varepsilon}$ estimator at grid point $\mathbf{M}_{i}=\left(x_{i}, y_{i}, t_{i}\right)$. over the period $\delta t=t_{b}-t_{a}$, where $x_{i}, y_{i}$ state for longitude and latitude and $t_{i}$ is the time

$t_{a}, t_{b}$ are the beginning and end time of the analysis. $N$ is the number of available and validated observations.

$X_{b o}^{j}$ is the $j$-th background surface parameter interpolated in space and time over satellite swath.

$X_{o}^{j}$ indicates the jth remotely sensed observation vector available over the satellite swath.

$\left(X_{o}^{j}-X_{b o}^{j}\right) j$-th is the difference between satellite observation and ECMWF analysis located in the space and time neighborhood of grid point $M_{i}$.

$\lambda$ is the weighting vector to be estimate. Its determination at each grid point leads to minimizing the residual

$R=\tilde{\varepsilon}-\hat{\varepsilon}$ with the unbiased constraint $\sum_{j=1}^{N} \lambda_{j}=1$ 
The Gauss Markov theorem indicates that the best estimator in the least-squares optimum linear estimator should minimize $\operatorname{Var}(R)=E\left((\tilde{\varepsilon}-\hat{\varepsilon})^{2}\right)$. Operator $E$ is the mathematical mean.

At a given grid point $M_{0}=\left(x_{0}, y_{0}, t_{0}\right)$.

$\operatorname{Var}\left(R\left(M_{0}\right)\right)=\operatorname{Var}\left(\tilde{\varepsilon}\left(M_{0}\right)\right)+\operatorname{Var}\left(\hat{\varepsilon}\left(M_{0}\right)\right)-2 \operatorname{Cov}\left(\tilde{\varepsilon}\left(M_{0}\right), \hat{\varepsilon}\left(M_{0}\right)\right)$

Cov indicates the covariance.

For each time step (one hour in practice) and using Eq. (2) the variance of $\hat{\varepsilon}\left(M_{0}\right)$ is:

$$
\begin{aligned}
\operatorname{Var}\left(\hat{\varepsilon}\left(M_{0}\right)\right)= & \operatorname{Var}\left(\sum_{j=1}^{j=N} \lambda_{j}\left(X_{o}^{j}-X_{b o}^{j}\right)\right) \\
= & E\left(\sum_{j=1}^{j=N} \lambda_{j}\left(X_{o}^{j}-X_{b o}^{j}\right)\right)^{2} \\
& -\left(\sum_{j=1}^{j=N} \lambda_{j} E\left(X_{o}^{j}-X_{b o}^{j}\right)\right)^{2} \\
\operatorname{Var}\left(\hat{\varepsilon}\left(M_{0}\right)\right)= & \sum_{j=1}^{j=} \sum_{l=1}^{l=N} \lambda_{j} \lambda_{l} E\left(\left(X_{o}^{j}-X_{b o}^{j}\right)\left(X_{o}^{l}-X_{b o}^{l}\right)\right) \\
& -\left(\sum_{j=1}^{j=N} \lambda_{j} E\left(X_{o}^{j}-X_{b o}^{j}\right)\right)^{2}
\end{aligned}
$$

Assuming that the difference between observation and analysis is homogeneous over the $M_{0}$ neighborhood (first intrinsic assumption):

$$
E\left(X_{o}^{j}-X_{b o}^{j}\right)=E\left(X_{o}^{l}-X_{b o}^{l}\right)=m \forall j, l=1, N
$$

This assumption states that the mean of the difference between observation and analysis is independent of the space and time separation. To assess such assumption, one month of interpolated ECMWF and QuikScat $10 \mathrm{~m}$ winds are used. Three temporal separations between the two sources are considered: $6 \mathrm{~h}, 12 \mathrm{~h}$, and $24 \mathrm{~h}$. The investigation is performed in boxes of $5^{\circ}$ in longitude and latitude over the Mediterranean Sea. Over each box and for each separation time, the mean value of difference $\tilde{\varepsilon}\left(M_{i}\right)-\tilde{\varepsilon}\left(M_{j}\right)$ is estimated as a function of spatial distance between $M_{i}$ and $M_{j}$ for wind speed, zonal, and meridional components. It is found (not shown) that the mean values of $\tilde{\varepsilon}\left(M_{i}\right)-\tilde{\varepsilon}\left(M_{j}\right)$ are very small and do not exceed $0.03 \mathrm{~m} / \mathrm{s}$. The Student's test establishes that the mean values are not statistically different from 0 .

Therefore Eq. (7) leads to

$$
\begin{aligned}
\operatorname{Var}\left(\hat{\varepsilon}\left(M_{0}\right)\right)= & \sum_{j=1}^{j=N} \sum_{l=1}^{l=N} \lambda_{j} \lambda_{l} E\left(\left(X_{o}^{j}-X_{b o}^{j}\right)\left(X_{o}^{l}-X_{b o}^{l}\right)\right) \\
& -\sum_{j=1}^{j=N} \sum_{l=1}^{l=N} \lambda_{j} \lambda_{l} m^{2}
\end{aligned}
$$

$\operatorname{Var}\left(\hat{\varepsilon}\left(M_{0}\right)\right)=\sum_{j=1}^{j=N} \sum_{l=1}^{l=N} \lambda_{j} \lambda_{l} \operatorname{Cov}\left(\left(X_{o}^{j}-X_{b o}^{j}\right),\left(X_{o}^{l}-X_{b o}^{l}\right)\right)$

Furthermore

$$
\begin{aligned}
\operatorname{Cov}\left(\tilde{\varepsilon}\left(M_{0}\right), \hat{\varepsilon}\left(M_{0}\right)\right) & =E\left(\left(\sum_{j=1}^{j=N} \lambda_{j}\left(X_{o}^{j}-X_{b o}^{j}\right)\right)\left(X_{o}^{0}-X_{b o}^{0}\right)-m^{2}\right. \\
& =\sum_{j=1}^{j=N} \lambda j \operatorname{Cov}\left(\left(X_{o}^{j}-X_{b o}^{j}\right),\left(X_{o}^{0}-X_{b o}^{0}\right)\right)(9)
\end{aligned}
$$

Therefore, using Eqs. (3), (8), and (9):

$\operatorname{Var}\left(R\left(M_{0}\right)\right)=\operatorname{Var}\left(\tilde{\varepsilon}\left(M_{0}\right)\right)+\sum_{j=1}^{j=N} \sum_{l=1}^{l=N} \lambda_{j} \lambda_{l} \hat{C}_{i j}-2 \sum_{j=1}^{j=N} \lambda_{j} \hat{C}_{i 0}$

where $\hat{C}_{i j}=\operatorname{Cov}\left(\hat{\varepsilon}\left(M_{i}\right), \hat{\varepsilon}\left(M_{j}\right)\right)$.

Minimizing functional $\operatorname{Var}\left(R\left(M_{0}\right)\right)$ in weighting space and under an unbiased constraint leads to the following linear system:

$$
\begin{aligned}
& \sum_{j=1}^{j=N} \lambda_{j} \hat{C}_{i j}-\mu=\hat{C}_{i 0} \text { for } i=1, N \\
& \sum_{j=1}^{j=N} \lambda_{j}=1
\end{aligned}
$$

$\mu$ is the Lagragian term used to take into account the unbiased constraint.

\subsection{Space and time structure}

The objective method requires parameterization of the spatial and temporal covariance structure of the difference between remotely sensed wind and the background NWP data. The approach used in Bentamy et al. (1996) is adapted for this study. First, the local spatial and temporal stationarity is assumed. Therefore, the covariance does not depend on the precise geographical location and epoch of data, but only on the separation in space and time.

$C(\delta h, \delta t)=\operatorname{Cov}\left(\tilde{\varepsilon}\left(M_{i}, t_{i}\right), \tilde{\varepsilon}\left(M_{j}, t_{j}\right)\right)$

Where $\delta h$ and $\delta t$ stand for spatial and temporal separation, respectively.

As the assessment of this assumption is not straightforward, the following assumption is considered:

$$
E\left(\tilde{\varepsilon}\left(M_{i}, t_{i}\right)-\tilde{\varepsilon}\left(M_{j}, t_{j}\right)\right)^{2}=G(\delta h, \delta t)
$$

$G$ is the spatial and temporal structure function of the difference variable $\tilde{\varepsilon}$. It is function only of the spatial separation, $\delta h$ between grid $M_{i}$ and $M_{j}$, and of the temporal separation, $\delta t$ between $t_{i}$ and $t_{j}$.

Using the first intrinsic assumption (Eq. 7), Eqs. (12) and (13):

$G(\delta h, \delta t)=2(C(0,0)-C(\delta h, \delta t))$ 

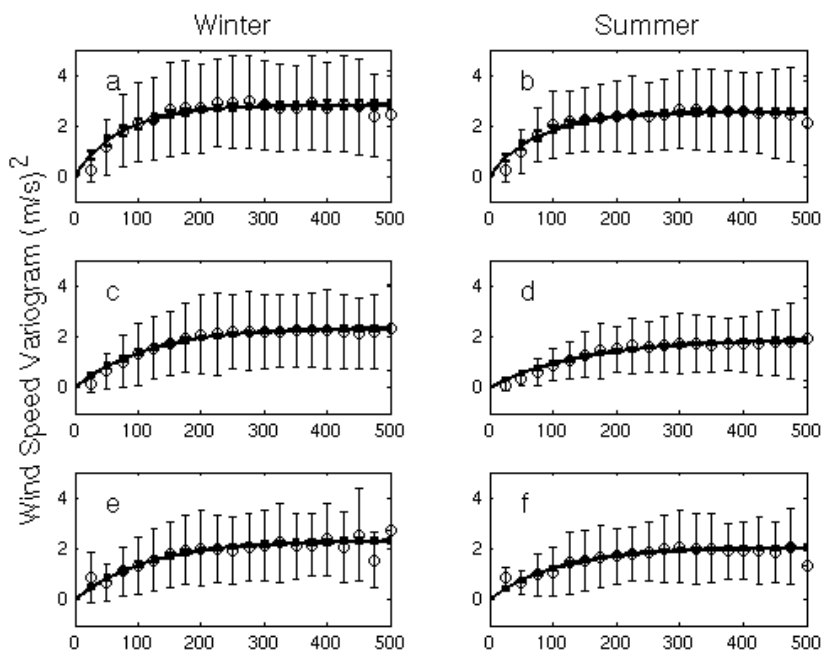

Fig. 1. Variogram function of $\overleftrightarrow{\varepsilon}$ variable estimated over $5^{\circ} \times 5^{\circ}$ boxes in the Mediterranean Sea for lag time less than $1 \mathrm{~h}$. The box is centered at $5^{\circ}$ intervals of longitude and longitude $4^{\circ} \mathrm{E}-42^{\circ} \mathrm{N}$. The spatial structure is estimated for wind speed (a and $\mathbf{b}$ ), zonal wind component (c and $\mathbf{d}$ ), and for meridional component (e and f). The figures show the behavior of the variogram as a function of spatial separation (in $\mathrm{km}$ ) estimated for winter and summer seasons.

In practice, the following structure function, called variogram, is used

$\Gamma(\delta h, \delta t)=C(0,0)-C(\delta h, \delta t)$

The objective is to determine a covariance matrix involving the main spatial and temporal structure of variable $\tilde{\varepsilon}$ without any prior gridding or spectral filtering. Therefore, the investigation of covariance or variogram behavior as a function of space and time separation is performed at several areas of the Mediterranean Sea. To calculate the sample covariance, the spatial and temporal collocated QuikScat and ECMWF wind data are used. The observed values of $\tilde{\varepsilon}$ are then calculated over each satellite WVC and stratified in terms of 1-hourly time windows (WVC time). Figure 1 shows an example of wind speed $\left(\tilde{\varepsilon}_{w}\right)$ variogram behaviors as a function of spatial separation for a lag time of less than one hour. They are estimated for winter and summer seasons over three $5^{\circ}$ boxes centered at $4^{\circ} \mathrm{E}-42^{\circ} \mathrm{N}, 19^{\circ} \mathrm{E}-36^{\circ} \mathrm{N}$, and $29^{\circ} \mathrm{E}-33^{\circ} \mathrm{N}$, respectively. As expected, the variogram increases with respect to increasing separation, notifying that correlation decreases with increasing spatial separation. The variogram estimations from observations exhibit high spread for all separation ranges mainly related to the high variability of $\tilde{\varepsilon}$ variable. Consequently, the parameterization of the covariance matrix should take into account such variation. Furthermore, the former should ensure that the covariance matrix is positivedefinite. Several formulations of positive-definite analytical function dealing with the empirical variogram fitting exist and are commonly used. In this study the following formulation is used:

$\hat{\Gamma}(\delta h, \delta t)=\varepsilon_{p}+a\left(1-\exp \left(-\frac{\delta h+c \delta t}{b}\right)\right)$

$\varepsilon_{p}, a, b, c$ are the variogram model parameters.

$\varepsilon_{p}$ stands for $\tilde{\varepsilon}$ noise. $b$ and $c$ are the spatial and temporal characteristic decorrelation scales, respectively. Parameter $a$, named sill value, indicates the variogram value reached for spatial and temporal ranges where variables are uncorrelated.

The variogram parameters are estimated as a minimum solution of:

$F\left(\varepsilon_{p}, a, b, c\right)=\left(\frac{\Gamma(\delta h, \delta t)-\hat{\Gamma}(\delta h, \delta t)}{\sigma(\delta h, \delta t)}\right)^{2}$

$\sigma^{2}(\delta h, \delta t)$ indicates the variance of the observed variogram.

The parameters are determined over several Mediterranean sub-basins using remotely sensed and ECMWF wind differences during winter and summer season (Northern Hemisphere). Table 2 provides $a, b$, and $c$ estimates and their accuracies in terms of 95 confidence intervals. The variable $\varepsilon_{p}$ is found to be small and remains nearly constant as a function of geographical area as well as a function of period. Therefore it is considered as negligible and set to zero. The changes in the variogram parameters $a, b$, and $c$ changes are significant with respect to geographical area and season. The highest spatial and temporal decorrelation length $(b)$ values are found.

\section{Accuracy of blended fields}

The previous method is used to estimate the gridded wind fields over the Mediterranean Sea. Even though several space and time resolutions are investigated, this section focuses on the derived wind fields with the spatial resolution of $0.25^{\circ}$ in longitude and latitude, and temporal resolution of $6 \mathrm{~h}$. The quality of the resulting near real time blended wind fields is investigated through several comparisons over the global basin as well as at some specific locations.

\subsection{Global analysis}

To evaluate the quality of the previous method, surface wind fields are calculated from near real time satellite and ECMWF winds. ECMWF wind analysis data are extracted from the GODIVA data base (http://www.nerc-essc.ac.uk/ godiva). They are made available with a delay less than $12 \mathrm{~h}$. Since January 2002, NRT QuikSCAT winds are assimilated into the ECMWF model. The surface variables used in this study are 10-m wind components, which are routinely produced by the 6-hourly analyses on a regular longitudelatitude grid of size $0.5625^{\circ} \times 0.5625^{\circ}$. For each ECMWF wind analysis available at synoptic time $(00: 00 \mathrm{~h} ; 06: 00 \mathrm{~h}$; 
Table 2. Example of variogram parameters estimated for wind speed, zonal wind component, meridional component differences (Satellite - ECMWF) over three oceanic $5^{\circ}$ box and during 2004 winter and summer seasons. The box is centered at $5^{\circ}$ intervals of longitude and longitude $4^{\circ} \mathrm{E}-42^{\circ} \mathrm{N}$. Numbers within brackets defined the $95 \%$ confidence interval.

\begin{tabular}{llllllllllll}
\hline & \multicolumn{3}{c}{ Wind speed } & \multicolumn{3}{c}{ Zonal wind } & \multicolumn{3}{c}{ Meridional wind } \\
& & $\mathrm{a}$ & $\mathrm{b}$ & $\mathrm{c}$ & $\mathrm{a}$ & $\mathrm{b}$ & $\mathrm{c}$ & $\mathrm{a}$ & $\mathrm{b}$ & $\mathrm{c}$ \\
\hline \multirow{2}{*}{ Winter } & \multirow{2}{*}{ Mediterranean sea } & 2.75 & 116 & 19 & 4.55 & 171 & 29 & 5.52 & 223 & 37 \\
& & {$[2.54$} & {$[66$} & {$[11$} & {$[3.92$} & {$[72$} & {$[12$} & {$[5.07$} & {$[157$} & {$[26$} \\
& & $2.97]$ & $166]$ & $28]$ & $5.17]$ & $271]$ & $45]$ & $5.98]$ & $288]$ & $48]$ \\
\hline \multirow{2}{*}{ Summer } & \multirow{2}{*}{ Mediterranean Sea } & 2.26 & 163 & 27 & 4.17 & 270 & 45 & 3.89 & 244 & 41 \\
& & {$[2.12$} & {$[116$} & {$[19$} & {$[3.72$} & {$[180$} & {$[30$} & {$[3.55$} & {$[174$} & {$[29$} \\
& & $2.41]$ & $209]$ & $35]$ & $4.06]$ & $360]$ & $60]$ & $4.22]$ & $315]$ & $52]$ \\
\hline
\end{tabular}

12:00 h; 18:00 h) all valid satellite data (scatterometer, radiometers) available within $3 \mathrm{~h}$ from ECMWF time are selected. An interpolation method is used to estimate ECMWF winds over each satellite wind cells:

$$
X_{b o}=\frac{1}{\sum_{i=1}^{i=N} \frac{1}{d_{i}}} \sum_{i=1}^{i=N}\left(\frac{1}{d_{i}} X_{b}\right)
$$

The variable $d i$ is the spatial separation between satellite wind cell and ith ECMWF grid point. $N$ is the number of ECMWF wind estimates provided at a given spatial distance from satellite wind cells.

The quality of the blended wind fields is mainly related to the accuracy of the remotely sensed data and to the spatial and temporal sampling scheme of the observations. Using all validated QuikScat and SSMI (F13, F14, and F15) retrieval winds, we can expect (on average) two observations within each grid point $\left(0.25^{\circ} \times 0.25^{\circ}\right)$ and within $3 \mathrm{~h}$ from ECMWF synoptic time. This number however varies according to space and time. For instance, in the western area $\left(6^{\circ} \mathrm{W}-10^{\circ} \mathrm{E}\right)$ the mean number of satellite observations exceeds 3 for $12: 00 \mathrm{~h}$ time analysis. Figure 2 illustrates such issue at a specific location. It shows the number of satellite observations during January 2004. It indicates that the observation length is not the same for the four synoptic time analysis. Furthermore, the sampling satellite wind observations are not uniform over the whole basin. Indeed, in open sea areas the number of satellite observations falling within each grid point $\left(0.25^{\circ}\right.$ resolution) and resulting for each epoch $(6 \mathrm{~h})$ is on average 3 . This number drops to less than 1 in nearshore areas and in the Aegean Sea. The impact of the satellite sampling scheme is investigated using a method previously published by several authors (e.g. Mestas et al., 1994; Bentamy et al., 1998). Briefly, in Eq. (7) the validated satellite observation is replaced by the nearest, in space and time, ECMWF analysis. The resulting wind fields are then compared to the 6-hourly operational ECMWF analyses during January 2004 and over the Mediterranean Sea. The overall statistics characterizing the difference between the two wind fields demonstrate that the bias and the standard deviation are quite small and do not exceed $0.50 \mathrm{~m} / \mathrm{s}$ for wind speed as well as for wind components. The correlation between the two fields is very high and about 0.99 . However, some high local differences are depicted. For instance in the Mistral track, characterized by high and variable surface winds, the difference at some grid points reaches $1 \mathrm{~m} / \mathrm{s}$ related to the smoothing of ECMWF winds used as observation and background, and to the satellite sampling schemes.

The longitude, latitude, and time of the satellite wind cell are associated to the variable $\tilde{\varepsilon}=X_{o}-X_{b o}$. A typical spatial distribution of $\tilde{\varepsilon}$ observations is shown in Fig. 3. It exhibits an interesting sampling length over the oceanic basin. High spatial variability is clearly depicted however, and provides an illustration of spatial and temporal structure function results obtained in a previous section.

For this study the $\tilde{\varepsilon}$ observations are derived from QuikScat-ECMWF (wind speed, zonal and meridional components) and from F13, F14, and F15 SSM/I-ECMWF (wind speed). At each SSM/I wind cell the wind direction is derived from the interpolated ECMWF analysis. The objective method is used to analysis $\tilde{\varepsilon}$ over the global ocean with a spatial resolution of 0.25 in longitude and latitude, and with temporal resolution of $6 \mathrm{~h}(00: 00 \mathrm{~h}, 06: 00 \mathrm{~h}, 12: 00,18: 00 \mathrm{~h})$. For a given epoch $\tilde{\varepsilon}$ observations are stratified in hourly time intervals and at each grid point, and data related to QuikScat are first selected to be used in the analysis. Figure 4 illustrates an example of the blended method result. It shows ECMWF wind field analysis of the 2 January 2004 at 12:00 $\mathrm{h}$ (Fig. 4a) and the corresponding blended wind product (Fig. 4b), remotely sensed wind observations (Fig. 4c), and satellite - ECMWF winds (Fig. 4d). As expected, the figure shows that blended wind data are close to satellite retrieved winds and the most of biases (Fig. 4d) are removed. This result is confirmed by the investigation of blended wind product consistency during January 2004 in various Mediterranean sub-basins. Table 3 summarizes the comparisons between satellite wind observations and blended data. The latter are interpolated over satellite swaths (Eq. 18). Results 
Table 3. Mean and root mean square (Rms) difference values, and correlation (cor) values characterizing satellite and blended wind speed, zonal and meridional wind component comparisons. Same statistical parameters are provided for satellite and ECMWF comparisons.

\begin{tabular}{lcccc}
\hline \multirow{2}{*}{ Wind speed } & & Bias $(\mathrm{m} / \mathrm{s})$ & $\mathrm{Rms}(\mathrm{m} / \mathrm{s})$ & Cor \\
\hline \multirow{2}{*}{ Zonal component } & Satellite/Blended & 0.00 & 0.25 & 0.99 \\
& Satellite/ECMWF & 0.96 & 1.84 & 0.96 \\
\hline \multirow{2}{*}{ Meridional component } & Satellite/Blended & 0.00 & 0.24 & 0.99 \\
& Satellite/ECMWF & 0.28 & 2.42 & 0.92 \\
\cline { 2 - 5 } & Satellite/Blended & 0.00 & 0.25 & 0.99 \\
& Satellite/ECMWF & -0.30 & 2.26 & 0.96 \\
\hline
\end{tabular}

Table 4. WMO ID and positions of moored buoy use to investigate the quality of Blended wind data.

\begin{tabular}{lcc}
\hline Basin & Buoy & Position (latitude, longitude) \\
\hline & 61001 & $43.40^{\circ} \mathrm{N}, 7.80^{\circ} \mathrm{E}$ \\
& 61002 & $42.10^{\circ} \mathrm{N}, 4.70^{\circ} \mathrm{E}$ \\
& 2008010 & $36.23^{\circ} \mathrm{N}, 5.03^{\circ} \mathrm{W}$ \\
Mediterranean Sea & 2029012 & $36.57^{\circ} \mathrm{N}, 2.34^{\circ} \mathrm{W}$ \\
& 2077055 & $41.91^{\circ} \mathrm{N}, 3.65^{\circ} \mathrm{E}$ \\
& 2083038 & $39.73^{\circ} \mathrm{N}, 4.42^{\circ} \mathrm{E}$ \\
& 3155039 & $43.63^{\circ} \mathrm{N}, 3.05^{\circ} \mathrm{W}$ \\
\hline \multirow{4}{*}{ Atlantic ocean } & 62001 & $45.20^{\circ} \mathrm{N}, 5.00^{\circ} \mathrm{W}$ \\
& 1050076 & $44.06^{\circ} \mathrm{N}, 7.61^{\circ} \mathrm{W}$ \\
& 1052046 & $44.06^{\circ} \mathrm{N}, 6.96^{\circ} \mathrm{W}$ \\
& 3002002 & $42.12^{\circ} \mathrm{N}, 9.40^{\circ} \mathrm{W}$ \\
& 3007036 & $43.49^{\circ} \mathrm{N}, 9.21^{\circ} \mathrm{W}$ \\
& 3080042 & $43.73^{\circ} \mathrm{N}, 6.16^{\circ} \mathrm{W}$ \\
\hline
\end{tabular}

related to satellite observation and ECMWF analysis comparisons are also shown too. On average, the bias between satellite observation and blended wind analysis is very low. The RMS values do not exceed $0.30 \mathrm{~m} / \mathrm{s}$. As seen from Table 3, both the pattern and the amplitude of the numerical analysis winds agree quite well with those derived from satellite measurements. The statistics related to the satellite and ECMWF comparisons are quite similar to those obtained over the global ocean (Monahan, 2006) indicating an overestimation of remotely sensed winds compared to ECMWF analysis. Although not shown, this agreement is particularly good within the regions off coasts. The main discrepancies are found in near coast areas. In the latter areas remotely sensed wind observations (mostly from QuikScat) are up to $2 \mathrm{~m} / \mathrm{s}$ stronger and have a weaker onshore component. Using much more moored buoys moored in North east and west Atlantic, and in North Pacific (NDBC buoy networks), the comparisons performed between satellite and buoys located offshore (more than $50 \mathrm{~km}$ far from coast) exhibit better results than those derived from collocated satellite and nearshore buoy data. For instance, when considering buoys moored off-shore, the wind speed and direction correlation values are 0.94 and 1 . 90, respectively. The rms difference values are about $1.50 \mathrm{~m} / \mathrm{s}$ for wind speed, and $17^{\circ}$ for wind direction. For buoys located near-shore (distance from land less than $30 \mathrm{~km}$ ), the wind speed and direction correlations decrease to 0.86 and 1.64 , respectively. Such discrepancies may be related to the accuracy of satellite retrievals near shore areas (Picket et al., 2003), and to the spatial smoothing used in the numerical analysis and the related spatial resolution. The comparisons between blended wind product and ECMWF analysis exhibit patterns quite similar to satellite and ECMWF. The mean and the standard deviation of the difference between blended and ECMWF wind speed, calculated over the whole Mediterranean Sea and during January 2004 , are about $1.03 \mathrm{~m} / \mathrm{s}$ and $1.50 \mathrm{~m} / \mathrm{s}$, respectively. The highest discrepancies between the two wind sources are located in nearshore and the Aegean sea. Thismight be related to the poor spatial and temporal satellite sampling.

\subsection{Comparison with buoy measurements}

The quality of the blended wind products is primarily investigated through comparisons with wind speeds and directions measured by moored buoys in the Mediterranean Sea. However to enhance the comparison quality, some moored buoy in the Atlantic areas, close to the Mediterranean Sea, are also used. The buoys are provided by Météo-France and Puertos del Estado in Spain. Table 4 indicates the buoy positions. Except buoy 62001, the buoy locations are ranged between 8 to $120 \mathrm{~km}$ off coast. Only buoys providing significant sampling length (more than 15 days) of wind measurements are used in these comparisons. Even though the buoy data are already assimilated in ECMWF analysis, they provide a valuable method to assess the quality and especially the temporal characteristics of the blended. Buoys supply hourly oceanic and atmospheric data. Atmospheric measurements are made at a height of about $4 \mathrm{~m}$. For comparison issues, the LiuKatsaros-Businger (LKB) model (Liu et al., 1979) is used to calculate $10-\mathrm{m}$ wind speeds at neutral conditions. 
Table 5. Statistics between winds derived from buoy measurements, blended products, ECMWF analysis, QuikScat and SSM/I observations.

\begin{tabular}{llcccccccc}
\hline & & \multicolumn{3}{c}{ Mediterranean } & \multicolumn{4}{c}{ Atlantic } \\
& & Bias & Std & Cor & $\mathrm{N}$ & Bias & Std & Cor & $\mathrm{N}$ \\
\hline \multirow{3}{*}{ Wind speed } & Buoy/Blended & -0.41 & 2.61 & 0.85 & 387 & -0.34 & 1.92 & 0.86 & 790 \\
& Buoy/ECMWF & 1.59 & 1.96 & 0.82 & 387 & 0.30 & 1.56 & 0.92 & 790 \\
& Buoy/QuikScat & -0.43 & 2.13 & 0.92 & 93 & -0.21 & 1.62 & 0.91 & 189 \\
Zonal comp. & Buoy/SSMI & 0.13 & 2.68 & 0.90 & 71 & -0.18 & 2.26 & 0.76 & 150 \\
& Buoy/Blended & 0.01 & 3.42 & 0.83 & 387 & -0.57 & 2.18 & 0.92 & 790 \\
& Buoy/ECMWF & -0.92 & 2.65 & 0.91 & 387 & -0.37 & 1.90 & 0.94 & 790 \\
Meridional comp. & Buoy/QuikScat & -0.28 & 4.28 & 0.76 & 93 & -0.14 & 2.57 & 0.90 & 189 \\
& Buoy/Blended & -0.81 & 2.86 & 0.88 & 387 & -0.96 & 2.52 & 0.91 & 790 \\
& Buoy/ECMWF & -0.06 & 1.94 & 0.93 & 387 & -0.54 & 2.00 & 0.94 & 790 \\
& Buoy/QuikScat & -0.91 & 4.01 & 0.84 & 93 & -0.91 & 2.60 & 0.90 & 189 \\
\hline
\end{tabular}

$10 \mathrm{~m}$ buoy winds are calculated from raw data and 6hourly averaged. The buoy data are collocated in space and time with ECMWF and blended winds as well as with remotely sensed wind observations. Table 5 shows statistics derived from all available buoy and blended, ECMWF, QuikScat, and SSM/I wind data. Even though the sampling length is small yielding to less meaning of the statistical parameters, some obvious results may point out. As expected and due to the assimilation of buoy in ECMWF analysis, buoy and ECMWF comparisons exhibit the highest correlation and the lowest standard deviation difference values. Blended winds exhibit quite similar statistics than QuikScat and SSM/I observations. Their correlations with buoy winds are high and exceed 0.80 , while the bias values indicate a slight overestimation of blended wind speed estimates (about $0.40 \mathrm{~m} / \mathrm{s}$ in the Mediterranean Sea, and $0.30 \mathrm{~m} / \mathrm{s}$ in the Atlantic basin). The statistics estimated at the Mediterranean and the Atlantic sites do not indicate significant difference, especially in wind speed. Indeed, using fischer test, the difference between the Mediterranean and the Atlantic correlation coefficients is not significant with $95 \%$ confidence. The differences are found in wind directions (zonal and meridional components) related to the orography impact and to the wind distribution. Indeed, about $25 \%$ of the Mediterranean buoy winds are lower than $4 \mathrm{~m} / \mathrm{s}$, while in the Atlantic the percentage is about $15 \%$. Excluding buoy winds lower than $4 \mathrm{~m} / \mathrm{s}$ yields to similar statistics in both ocean areas.

The differences between 6-hourly averaged buoy and blended winds involve the satellite sampling schemes discussed in the previous section. Indeed, in the vicinity (spatial distance less than $25 \mathrm{~km}$ ) of the two off-shore Mediterranean buoys 61001 and 61002 (Table 4), on average three satellite wind observations are expected within a given epoch (Fig. 2). Most of the observations occurred between 03:00 a.m. and 09:00 a.m. and between 03:00 p.m. and 09:00 p.m. To investigate the impact of such sampling on the statistics characterizing the difference between buoy and blended wind data (Ta- ble 5), the hourly buoy data occurring half an hour from satellite observations and three hours from synoptic time $(00: 00 \mathrm{~h}$, 06:00 h, 12:00 h, 18:00 h) are collected and averaged. These are called simulated buoy data. The latter are compared to the 6-hourly averaged buoy data use to estimate the accuracy of blended wind estimates. During January 2004 the rms difference between 6-hourly averaged buoy and simulated buoy wind speed, zonal component, and meridional component are $1.20 \mathrm{~m} / \mathrm{s}, 1.14 \mathrm{~m} / \mathrm{s}$, and $1.29 \mathrm{~m} / \mathrm{s}$, respectively for 61001 buoy. For buoy 61002 , these quantities are $1.02 \mathrm{~m} / \mathrm{s}$, $1.00 \mathrm{~m} / \mathrm{s}$, and $1.10 \mathrm{~m} / \mathrm{s}$, respectively. These examples illustrate that the rms differences between buoy and blended data are a combination of several errors related to the difference between buoy measurements and remotely sensed wind observations, to the sampling scheme issue, and to the objective method.

Even though some significant buoy-to-buoy differences are found, the blended wind estimates capture the main wind temporal patterns at each buoy position. For instance, Figs. 5-7 show time series of wind speed, zonal wind component, and meridional components from blended (heavy line), ECMWF (dashed line), and from 61001, 61002, and 2029012 buoys (light line), respectively. They illustrate the good agreement between the three sources and indicate that the main fast wind changes as well as the high wind conditions measured by buoys are retrieved by blended. Indeed, considering only wind speeds higher than the third percentile estimated from buoy measurements, allows another insight into comparison results. In the Mediterranean Sea and during January 2004, the buoy wind speed third percentile is $10.28 \mathrm{~m} / \mathrm{s}$. The percentage of blended winds exceeding this percentile is $26 \%$, while for ECMWF it is $18 \%$. Such results indicate that high wind condition, generally associated with high spatial and temporal variation, are well retrieved. 


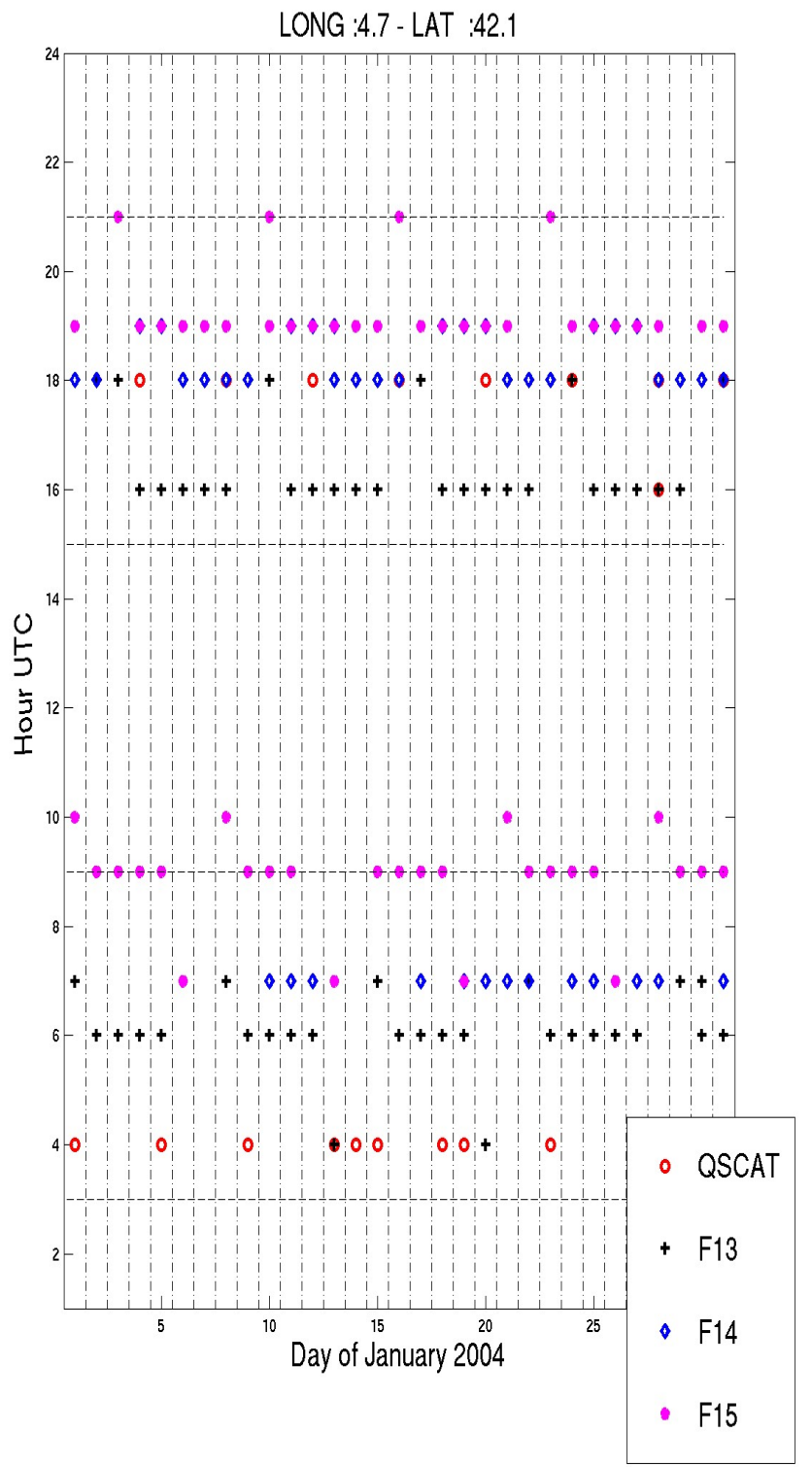

Fig. 2. Remotely sensed wind data availability during January 2004 and as function of UTC hour at the Mediterranean location $42.10^{\circ} \mathrm{N}-4.70^{\circ} \mathrm{E}$.

\section{Summary and conclusions}

A method was presented, validated, and used to estimate one month of gridded wind fields over the Mediterranean Sea with high spatial and temporal resolution. It is mainly based on the use of several remotely sensed surface winds (wind speed, zonal and meridional components), derived from scatterometer onboard QuikSCAT satellite, and SSM/I radiometers onboard DMSP F13, F14, and 15 satellites, in combination with winds from the operational ECMWF analysis available at synoptic time. The two kinds of wind sources were blended through the objective analysis of their differences, calculated over each individual satellite swath, based

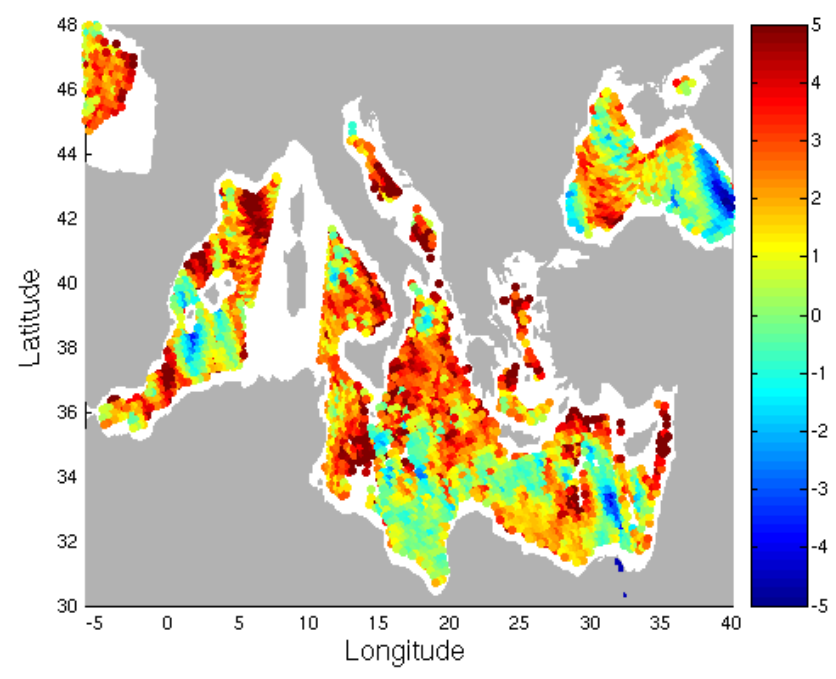

Fig. 3. Example of $\tilde{\varepsilon}_{w}$ observations (remotely sensed (QuikScat and $\mathrm{SSM} / \mathrm{I})$-ECMWF wind speed in $\mathrm{m} / \mathrm{s}$ ) during the period 1 January 2004 03:00 a.m.-09:00 a.m.
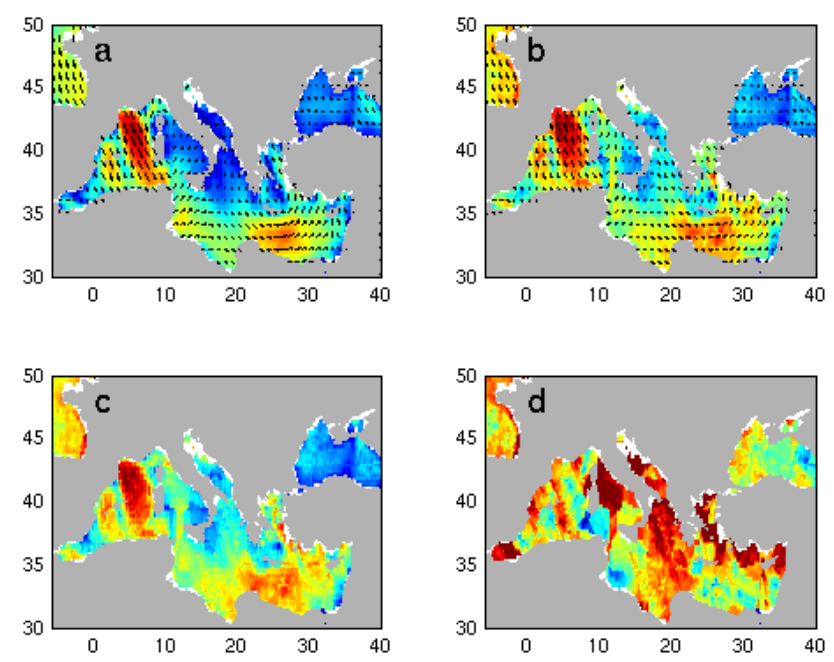

Fig. 4. Example of blended method result obtained for 2 January 2004 12:00 h: (a) ECMWF surface wind analysis; (b) blended wind product; (c) remotely sensed wind speed observations; (d) remotely sensed minus ECMWF wind speeds. Wind speed is ranged between $0 \mathrm{~m} / \mathrm{s}$ (blue color) and $20 \mathrm{~m} / \mathrm{s}$ (red color), while wind speed difference is ranged between $-5 \mathrm{~m} / \mathrm{s}$ and $5 \mathrm{~m} / \mathrm{s}$.

on the kriging approach. The requested wind speed, zonal and meridional variograms were estimated from the observed ECMWF-QuikSCAT wind differences. It was shown that the main parameters characterizing their behaviors as a function of spatial and temporal separations may change according to sub-basin. As blended wind fields were only estimated for January 2004, the empirical variogram determined during winter season was used. Further refinements will be attempted in order to include the seasonal and regional 


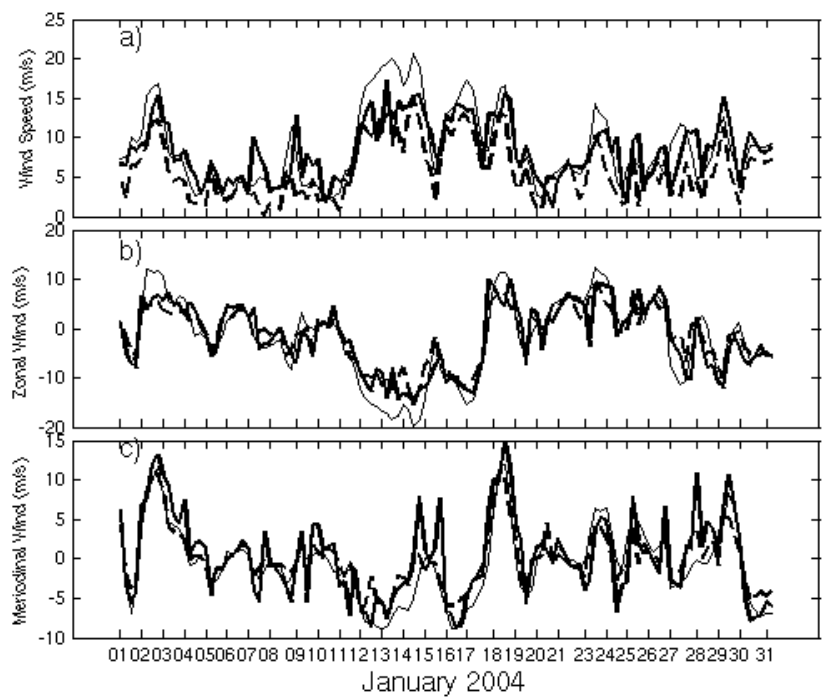

Fig. 5. Time series of wind speed (a), zonal wind component (b), and meridional wind component (c) derived from buoy (light line), blended product (heavy line), and from ECMWF analysis (dashed line) at buoy location $43.40^{\circ} \mathrm{N}-7.80^{\circ} \mathrm{E}$ (buoy 61001).

variogram behavior. However, the impact of the variogram on the blended error is lower than the accuracy of each remotely sensed wind and the satellite instrument sampling scheme. Indeed, the use of near real time retrieval scatterometer and radiometer winds requested validation issues. They were performed through comparisons to the associated offline winds. The main results are the adaptation of KNMI rain flag for QuikSCAT winds and the correction of SSM/I winds using an empirical model based on the collocation of QuikSCAT and SSM/I winds on the global ocean. Furthermore, this study indicates that the quality of blended wind vector fields strongly depends on the satellite observation time. The simulation of the impact of such time sampling was investigated using buoy data and indicated for instance that the wind speed error may exceed $1 \mathrm{~m} / \mathrm{s}$. The resulting blended wind fields were verified by comparison with the satellite wind observations as well with buoy measurements at several Mediterranean sea location, including nearshore buoys. As buoy data are assimilated into ECMWF analysis they cannot be considered independent. As expected, blended and averaged satellite wind observations exhibit very high correlation coefficients (about 0.99 ) and very low biases. The agreement between blended and the 6-hourly averaged buoy wind estimates is good. The correlation coefficients are quite high (exceeding 0.85). The statistical parameters characterizing the differences between buoy and blended data are quite similar to those obtained from buoy and satellite comparisons. However, the data set of this study is quite small thus yielding less significance to the statistical parameters. The latter found in this study are highly related to the atmosphere and oceanic conditions during Jan-

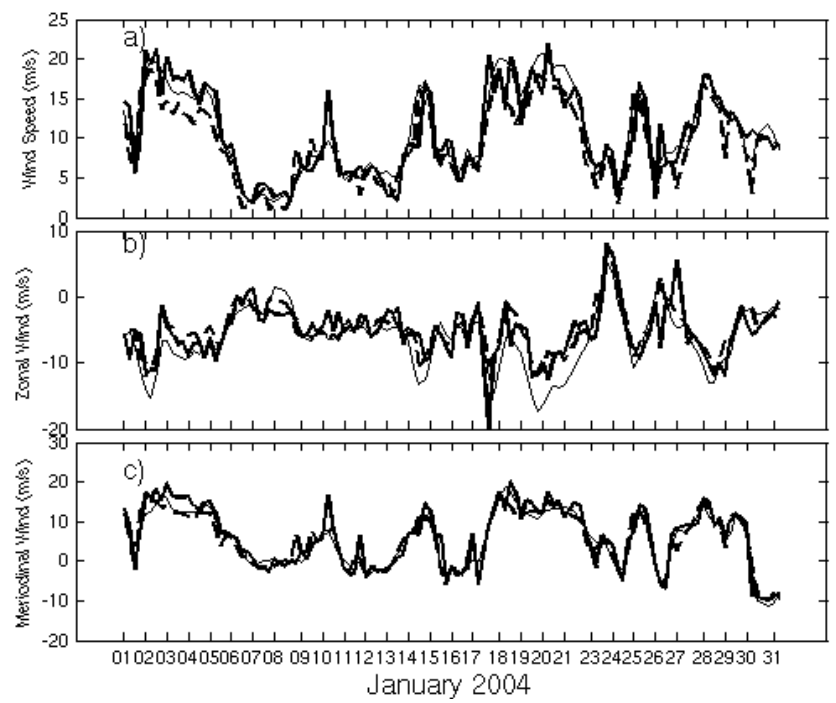

Fig. 6. As Fig. 5 at buoy location $42.10^{\circ} \mathrm{N}, 4.70^{\circ} \mathrm{E}$ (buoy 61002).

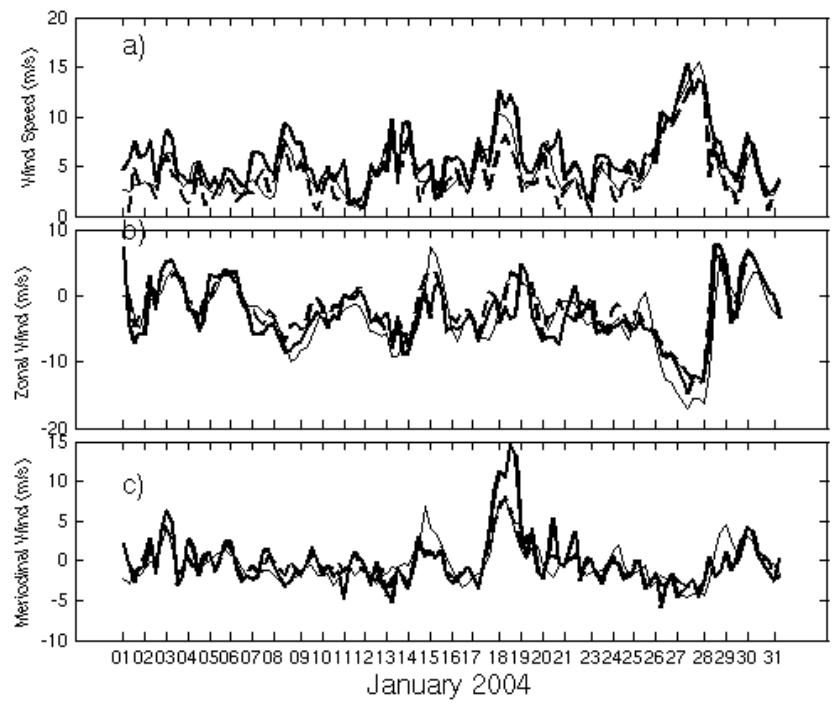

Fig. 7. As Fig. 5 at buoy location $36.57^{\circ} \mathrm{N}-2.34^{\circ} \mathrm{W}$ (buoy 2029012).

uary 2004. Furthermore, the use of a small collocated data emphasizes the main problem related to the comparison of moored buoy to satellite data: satellite data are asynoptic and have complex swath based spatial coverage patterns, while buoy sampling is $8 \mathrm{~min}$ averaging on the hour and the derived wind vector is strongly related to the local wind condition. Therefore, to assess the quality of the near real time blended wind fields, longer (more than 3 years) time series are obviously needed and recommended.

In the future, more satellite wind data will be involved in the blended analysis. Indeed, since 2003 the experiment satellite Windsat provides an estimation of ocean vector winds from polarimetric microwave radiometers. Next 
June 2006, the satellite METOP will be launched with a new scatterometer onboard providing surface winds with a spatial resolution of $0.25^{\circ} \times 0.25^{\circ}$. In parallel, the accuracy of the blended long time series will be investigated through their impact $\mathrm{n}$ oceanic circulation model forcing experiments.

Acknowledgements. This study was funded by Mediterranean Forecasting Towards Environmental Predictions (MFSTEP) and by Marine and EnviRonment and Security for European Area (MERSEA) European integrated projects. We thank CERSAT and Météo-France teams for help with processing the raw satellite near real time data. We thank M. L. Quentel and K. Whitmer for their comments and writing correction. We are grateful to the institutes that maintain buoy networks and make available high quality surface parameters estimates (Météo - France; UK Met Office, EPEE).

Edited by: N. Pinardi

\section{References}

Atlas, R. M., Hoffman, R. N., Bloom, S. C., Jusem, J. C., and Ardizzone, J.: A multiyear global surface wind velocity dataset using SSM/I wind observations., Bull. Am. Meteorol. Soc., 77, 869$882,1996$.

Liu, W. T., Tang, W., and Polito, P. S.: NASA Scatterometert provides global ocean-surface wind fields with more structures than numerical weather prediction, Geophys. Res. Lett., 25(6), 761764, 1998.

Bauer, E.: Characteristic frequency distributions of remotely sensed in situ and modeled wind speeds, Int. J. Climatol., 16, 1087$1102,1996$.

Bentamy, A., Quilfen, Y., Gohin, F., Grima, N., Lenaour, M., and Servain, J.: Determination and validation of average field from ERS-1 scatterometer measurements, Global Atmos. Ocean Sys., 4, 1-29, 1996.

Bentamy, A., Grima, N., and Quilfen, Y.: Validation of the gridded weekly and monthly wind fields calculated from ERS-1 scatterometer wind observations, The Global Atmosphere and Ocean System, 6, 373-396, 1998.

Bentamy, A., Queffeulou, P., Quilfen, Y., and Katsaros, K.: Ocean surface wind fields estimated from satellite active and passive microwave instruments, IEEE Trans. Geosci. Remote Sens., 37, 2469-2486, 1999.

Bentamy, A., Katsaros, K. B., Alberto, M., Drennan, W. M., and Forde, E. B.: Daily surface wind fields produced by merged satellite data. Gas Transfer at Water Surfaces, Geophysical Monograph 127, Copyright 2002 by the American Geophys. Union, 343-349, 2002.

Bentamy A., Ayina, H. L., and Queffeulou, P.: Investigation of the accuracy of the gridded satellite wind fields over the Mediterranean Sea: Comparisons with ECMWF wind estimates, MFSTEP report 3330, http://www.bo.ingv.it/mfstep/WP3/, 2005.

Bourassa, M. A., Legler, D. M., O’Brien, J. J., and Smith, S. R.: SeaWinds validation with research vessels, J. Geophys Res., 108(C2), 3019, doi:10.1029/2001JC001028, 2003.

Boutin, J., Etcheto, J., Rafizadeh, M., and Bakker, D. C. E.: Comparison of NSCAT, ERS 2 active microwave instrument, special sensor microwave imager, and Carbon Interface Ocean Atmo- sphere buoy wind speed: Consequences for the air-sea CO2 exchange coefficient, J. Geophys. Res., 104, 11 375-11 392, 1999.

Brody, L. R. and Nestor, M. J. R.: Regional Forecasting Aids for the Mediterranean Basin (Handbook for Forecasters in the Mediterranean, Part 2).Naval Research Laboratory, 7 Grace Hopper Avenue, Monterey, California, 93943-5502, 178 pp, 1980.

Chen, G.: An Intercomparison of TOPEX, NSCAT, and ECMWF Wind Speeds: Illustrating and understanding Systematic Discrepancies, Mon. Wea. Rev., 132, 780-792, 2003.

Chin, T. M., Milliff, R. F., and Large, W. O.: Basin scale, highwavenumber sea surface wind fields from a multiresolution analysis of scatterometer data, J. Atmos. Ocean. Technol., 15, 741763, 1998

Crapolicchio, R., Lecomte, P., and Hersbach, H.: Assimilation of reprocessed ERS scatterometer data into ECMWF weather analysis on the Mediterranean Sea, Adv. Geosci., 2, 327-329, 2005, http://www.adv-geosci.net/2/327/2005/.

Ebuchi, N., Graber, H. C., and Caruso, M. J.: Evaluation of wind vectors observed by QuikSCAT/SeaWinds using ocean buoy data, J. Atmos. Oceanic Technol., 19, 2049-2062, 2002.

Gaffard, C. and Roquet, H.: Impact of ERS-1 scatterometer wind data on the ECMWF 3D-Var assimilation system, Tech Memorandum no 217, ECMWF, 1995.

Goodberlet, M. A., Swift, C. T., and Wilkerson, J. C.: Remote sensing of ocean surface winds with the Special Sensor Microwave/Imager, J. Geophys. Res., 94, 14 547-14 555, 1989.

JPL: QuikScat science data product user's manual (version 2.0). Jet Propulsion Laboratory Publ. D-18053, Pasadena, CA, 84pp, available online at http://podaac.jpl.nasa.gov/quikscat, 2001.

Komen, G. J., Cavaleri, L., Donelan, M., Hasselmann, K., Hasselmann, S., and Janssen, P. A. E. M.: Dynamics and Modelling of Ocean Waves, Cambridge University Press, 532 p, 1994.

Liu, W. T., Katsaros, K. B., and Businger, J. A.: Bulk parameterization of air-sea exchanges of heat and water vapor including the molecular constraints at the interface, J. Atmos. Sci., 36, 17221735, 1979.

Long, D. E. and Mendel, J. M.: Identifiability in wind estimation from wind scatterometer measurements, IEEE Trans. Geosci. Remote Sens., GE-29, 268-276, 1991.

Meissner, T., Smith, D., and Wentz, F. J.: A 10-year intercomparison between collocated SSM/I oceanic surface wind speed retrievals and global analyses, J. Geophys. Res., 106(C6), 11731$11742,2001$.

Mestas-Nunez, A. M., Chelton, D. B., Freilich, M. H., and Richman, J. G.: An evaluation of ECMWF-based climatological wind stress fields, J. Phys. Oceanogr., 24, 1532-1549, 1994.

Milliff, R. F., Large, W. G., Monel, J., Danabasoglua, G., and Chin, T. M.: Ocean general circulation model sensitivity to forcing from scatterometewrinds, J. Geophys. Res., 104, 11 337-11358, 1999b.

Monahan, A. H.: The Probability Distribution of Sea Surface Wind Speeds Part II: Data set Intercomparison and Seasonal Variability, J. Climate, 19(4), 521-534, 2006.

Picket, M. H., Tang, W., Rosenfeld, L. K., and Wash, C. H.: QuikSCAT satellite comparisons with nearshore buoy wind data off the U.S. west coast, J. Atmos. Oceanic Technol., 20, 18691979, 2003.

Portabella, M. and Stoffelen, A.: A comparison of KNMI quality control and JPL rain flag for SeaWinds, Can. J. Rem. Sens., 
28(3), 424-430, 2002.

Queffeulou, P.: Wave height variability over the Mediterranean Sea, using altimeter data, Proceedings of the Fifth International Symposium on Ocean Wave Measurements and Analysis, Waves 2005, Madrid, 3-7 July 2005.
Sobieski, P. W., Craeye, C., and Bliven, L. F.: Scatterometric signatures of multivariate drop impacts on fresh and salt water surfaces, Int. J. Rem. Sens., 20, 2149-2166, 1999. 